indicación y el imperativo propios de la ley se fundían en la naturaleza racional del hombre, que se inclinaba ya hacia el bien. La autora lo dice claramente: «L'imperium è, cioè, un atto dei intelletto, che solo formalmente si manifesta come voluntas, ma che voluntas non è» (p. 56).

De esta forma, el jesuita se opuso radicalmente a la difusión de las ideas voluntaristas de Escoto y Ockham, afirmando una fundamentación de naturaleza como intrínsecamente racional, muy lejos de las concesiones escotistas de Suárez. Cintia Faraco ha rehuido deliberadamente de cualquier comparación con Suárez y con Molina, si bien resultaría iluminador proyectar algún trabajo en este sentido, especialmente con Molina, pues existen numerosos estudios con una orientación y finalidad similar, como el libro de Antonio Queralt, S.I., Libertad humana en Luis de Molina, Granada, Facultad de Teología, 1977, que permi-tirían una apertura a tesis más generales sobre la forma racional de la naturaleza en el seno de la escolástica jesuítica.

La autora concluye afirmando que si Vázquez «può esser ascritto a un tomismo filo-agostinista, ma con la precisazione che l'espresione 'filo-agostinista' voglia indicare una connessione più diretta con Gregorio e soltanto indiretta al pensiero dell'Ipponate» (p. 122). Se trata de una tesis fuerte, que limita la influencia de los autores del siglo XVI y de la propia Compañía de Jesús en la formación intelectual de Vázquez, y que vincula al jesuita de Belmonte en la avanzadilla del (neo)agustinismo, que tanta influencia tuvo sobre todo en el siglo XVII. Cabría ver si los «vazquistae», los epígonos que tuvo el pensador de Belmonte en el siglo XVII, siguieron las tesis de su maestro.

Hay que señalar, por último, que Cintia Faraco es una autora sutil, atenta siempre a la lectura directa con las fuentes y con un buen dominio de la filosofía, así como también una buena sintetizadora de los estudiosos contemporáneos de la obra de Vázquez. De momento, este libro ha hecho una contribución interesante y bien escrita a los estudios de la filosofía de Vázquez, sin renunciar al examen juicioso de las cuestiones metafísicas y descendiendo a las consecuencias jurídico-prácticas que se derivan de las premisas asumidas. Por todo ello, esta obra Cintia Faraco merece la atención de todos los lectores interesados.

RAFAEL RAMIS BARCELÓ

Universitat de les Illes Balears - IEHM

\title{
MARIA ALESSANDRA BILOTTA (ed.), GERARDO BOTO VARELA (intro), XAVIER BARRAL I ALTET (conclusions), Medie-val Europe in Motion. Palermo, Officina di studi medievali, 2018, 441 pp., ISBN: 9788864851068
}

Mobilidade e circulação. Estes conceitos dão o mote para os trabalhos reunidos no presente volume, cuja edição ficou a cargo de Maria Alessandra Bilotta, investigadora pós-doutoral do Instituto de Estudos Medievais da Universidade Nova de Lisboa. Sugestivamente intitulado «Medieval Europe in Motion» e subtitulado «The circulation of Artists Images Patterns and Ideas from the Mediterranean to the Atlantic Coast $\left(6^{\text {th }}-15^{\text {th }}\right)$ ) o conjunto de estudos reunidos resulta da conferência realizada em Lisboa em 2013 com o mesmo nome. Reúne 25 trabalhos de investigadores da Península Ibérica, Espanha e França e engloba textos redigidos em diferentes línguas (inglês, francês, português, italiano e espanhol).

Este volume põem a tónica na questão da circulação e na mobilidade na Europa medieval, com especial enfoque no mundo da cultura material, especialmente no que diz respeito à produção manuscrita e artística peninsular. O volume está estruturado em seis capítulos, organizados tematicamente.

A primeira observação que cumpre salientar após a leitura destes textos diz respeito à tipologia da circulação e da mobilidade propriamente dita. Assim, pode-se dizer que a circulação se opera de três formas: movimentação de objetos propriamente ditos (objetos que «migram» de um espaço geográfico a um outro), movimentação de modelos (veiculados pelo deslocamento dos artesãos/artistas que reproduzem/recriam um novo objeto artístico ou pela (re)produção local de artefactos em circulação), e, no caso especifico da cultura 
escrita, através tradução de textos (que implica um duplo movimento). Contudo, e segundo o artigo de JeanMarie Guillouët, que aborda a questão da circulação a partir do estudo do gótico, é também importante complementar este conceito com a noção de transferência, noção essa que permite dar conta da dimensão social e política associada à mobilidade de objetos, ideias e artistas. Assim, é impossível dissociar o movimento e a circulação de artefactos da movimentação de pessoas e instituições que não intervém diretamente no processo de criação artística.

Neste sentido, é, pois, necessário traçar uma distinção entre patronos e artistas. Esta diferença é importante porque, como diz Gerardo Boto Varela, na sua excelente introdução ao volume, o objeto pode ser transportado ou adquirido por um patrono, mas a técnica é indissociável do artista que a domina. Como tal, a presença física de artistas num determinado local permite a aplicação direta de diferentes técnicas nesse espaço, catalizando assim a criação de novos artefactos.

Vários artigos do presente volume procuram, pois, prestar esclarecimentos sobre a mobilidade de artistas e sobre a sua circulação no espaço europeu. Partindo do estudo comparativo de portefólios de artistas do século XIII, o artigo de Ludovico V. Geymonat avalia a importância que o caderno de rascunhos dos artistas desempenhava na produção artística dos mesmos tros trabalhos neste volume pro-curam dar conta da movimentação dos artistas e de artesãos, sobretudo da presença de estrangeiros em Portugal.

Refletem sobre estes aspetos a propósito do Românico português: o de Jorge Rodrigues reflete sobre a participação de artistas, escultores e mestres de outros pontos da Península Ibérica, sobretudo da Galiza, na conceção e construção de várias obras arquitetónicas do desse movimento artístico. Paulo Almeida Fernandes procura apurar a origem e identidade dos construtores/artistas do Românico português do século XII. Importante dado aportado por este estudo é a identificação de inúmeros construtores e ourives oriundos das comunidades judaica e muçulmana do território português.

Os trabalhos de Carla Varela Fernandes e de Pedro Flor discutem a participação de artistas e artesãos extrapeninsulares das mais variadas artes e ofícios (escultores, mestres de obras ourives e oleiros, carpinteiros e marceneiros etc.) na produção arquitetónica e artística portuguesa. Estes artigos mostram que a presença de artesãos oriundos de outros reinos ibéricos, da França, da Flandres, do Sacro-Império, etc., colocam Portugal em convergência com as correntes estéticas e artísticas do resto da Europa. Este dinamismo extravasa até as fronteiras europeias como mostra o artigo de Luís Urbano Afonso dedicado ao estudo da produção artística em marfim na atual Serra Leoa no século XVI.

Quanto aos objetos, modelos e artefactos, vários artigos evidenciam como a circulação de bens culturais depende de movimentações de conjuntos de indivíduos. Em alguns casos, esse movimento ocorre em primeiro lugar por razões políticas e está estritamente ligado aos casamentos régios: o artigo de Ana Maria Rodrigues mostra o enriquecimento cultural que os casamentos de alguns reis da Península Ibérica com rainhas nascidas em geografias transpirenaicas trouxeram ao espaço ibérico. Vai no mesmo sentido o artigo de Graça Videira Lopes, que debate a questão das relações da poesia trovadoresca occitânica e, embora em menor grau, com a poesia dos trouvères do norte da França com a poesia galego-portuguesa, e onde se postula a hipótese de as rainhas consortes portuguesas terem desempenhado um papel de facilitadoras no processo de transferência poética. Centrando-se sobretudo na promoção artística e não literária, o artigo de Maria Victoria Herraz Ortega aponta também para a importância da movimentação das infantas leonesas para o sul de França ou rainhas provenientes de outros pontos da Europa na disseminação de novos modelos arquitetónicos, escultóricos e figurativos nesse espaço geográfico. O trabalho de Delmira Espada Custódio incide nos aspetos artísticos e codicológicos do Livro de Horas de Dona Leonor, mulher de Dom João II tentando fornecer pistas para a sua origem e trajeto. O papel das mulheres das famílias reais (esposas, filhas, irmãs) na circulação de objetos, modelos e artistas é, pois, outro interessante aspeto evidenciado por vários artigos deste volume.

No que toca aos objetos propriamente ditos, são os artefactos ligados à cultura da escrita que merecem a maior atenção. O estudo de Augusto Aires Nascimento reflete sobre a importância da circulação de códices e manuscritos como elemento estruturador de um determinado espaço cultural, mostrando ainda que a produção 
de manuscritos e códices foi fundamental na construção da identidade europeia no período de transição da Tardo-Antiguidade para a Idade Média, sobretudo no âmbito do monaquismo cristão. A importância do códice como objeto determinante na identidade e vivência diária de comunidades religiosas ou de indivíduos é também destacada noutros artigos do volume. O artigo de Catarina Barreira sobre o Missal Alcobacense, códice elaborado no início do século XIV, mostra como a produção/aquisição de códices por parte desta comunidade monástica portuguesa é determinante na definição quer da sua identidade local, quer das suas relações com as comunidades cistercienses de outros pontos da Europa. Por seu lado, Delmira Espada Custódio e Ana Lemos contribuem com estudos dedicado aos Livros de Horas de alguns membros da família real portuguesa do século XV. O primeiro centra-se o Livro de Horas de Dona Leonor, mulher de Dom João II, e o segundo, no do rei Dom Duarte. Ambos os trabalhos realçam os princípios estéticos, artísticos e iconográficos que caracterizam cada um destes códices e procurando traçar o seu itinerário. Lidos em conjunto, os dois artigos permitem apreciar os paralelismos e diferenças entre a produção, receção e circulação deste tipo de códices ao mesmo tempo que deixam entrever a sua relação com as práticas devocionais privadas da família real portuguesa no século $\mathrm{XV}$.

Embora a distinção entre livros «monásticos» de uso comunitário e livros «aristocráticos» de uso privado exista, ela nem sempre é aplicável. O artigo de Luís Correia de Sousa dedicado ao estudo da chamada Bíblia do Abade, códice do século XIII, presente no Mosteiro de Alcobaça mas produzido para uso privado de um clérigo de alto rango alerta precisamente para a dificuldade de pensar certos temas à luz de categorias estanques, mostra como os dois mundos se entrecruzam neste códice.

O patrocínio e desenvolvimento artístico do espaço peninsular por parte de figuras régias, da aristocracia ou do clero não se limita à cultura escrita. O artigo de Esther Lozano López mostra como o século XII representou um momento de mudança na decoração das ábsides do Românico nos reinos de Castela, Aragão e Navarra, estabelece uma a relação entre essa renovação artística e o patrocínio dos reis e clérigos que habitavam esses espaços.

Outro tópico abundantemente tratado no conjunto dos artigos é o da circulação de modelos (sobretudo do ponto de vista da receção). Da autoria de Christian Heck chega-nos uma reflexão sobre o conceito de modelo e os seus diferentes usos. Fundamental para a compreensão desta noção parece ser aquilo que o autor chama de «Princípio de afinidade», que preconiza a distinção entre representação iconográfica (formal) e aquilo que é representado (conteúdo). A utilização de um determinado modelo pode ocorrer apenas num destes níveis (formal ou semântico), facto que o autor ilustra com vários exemplos. Dois artigos reportam-se à circulação de modelos bíblicos: a contribuição de Chiara Ruzzier aborda a disseminação do modelo gráfico da Bíblia concebido em Paris pela Europa meridional durante o século XIII. Conjugando os dados recolhidos neste artigo, com o trabalho já mencionado de Luís Correia de Sousa sobre a Bíblia do Abade, pode apreciar-se a dimensão da influência da Bíblia parisina na Europa do Sul. O artigo de Isabel Escandell aborda a mesma temática, concentrando-se na receção das bíblias originárias do território francês na Catalunha do século XIII, dando conta das fases do processo de disseminação (receção, adoção e produção) destes códices. Por fim, o extenso artigo de Maria Alessandra Bilotta, onde se traça uma descrição codicológica e iconográfica de um conjunto de manuscritos (ou fragmentos de manuscritos) jurídicos, permite traçar um panorama muito detalhado dos modelos iconográficos e estilísticos dos manuscritos jurídicos em circulação entre no sul de França nos séculos XIII e XIV, onde vislumbra a importância de regiões adjacentes, como a França do norte e a Itália na conceção de tais obras.

Outros artigos oferecem ainda visões interessantes e imaginativas do tópico central deste volume, traçando algumas pontes reflexivas com a modernidade. $\mathrm{O}$ artigo de Geraldo Boto Varela, oferece um panorama sobre o conceito de mobilidade na filosofia clássica e medieval ate aos dias de hoje. $\mathrm{O}$ artigo de Covadonga Valdaliso, que aporta uma original e interessante reflexão sobre a presença de mapas em alguns códices do século XIII da biblioteca de Sant Albans parte para uma reflexão sobre o dinamismo implícito do itinerário versus o estatismo da imagem, terminando com uma reflexão sobre a relação entre o medievalista contemporânea e o uso da imagem digital como recurso de trabalho. $\mathrm{O}$ uso de meios digitais no estudo dos manuscritos medievais 
e de uma tradição manuscrita é também tema do artigo de Marco Cursi que estuda a tradição manuscrita petrarquista.

Perante um conjunto de estudos tão variado, não é fácil para o editor encontrar uma organização interna plenamente satisfatória. No entanto, talvez tivesse sido possível optar por uma distribuição mais equitativa dos artigos, já que o número de artigo por capítulo é um pouco desigual: por exemplo, apenas existem dois artigos nos capítulos 3 e 5, mas deparamo-nos com seis nos capítulos 4 e 6, enquanto que os capítulos 1 e 2 contam com três artigos cada um.

Pondo de lado estes aspetos, cuja importância é, na verdade, pouco relevante, é evidente que o trabalho editorial exigido por um volume tão extenso é muito cuidadoso. A inclusão de uma introdução e de uma conclusão, dão ao volume uma sólida estrutura. A incorporação de reproduções a preto e branco como apêndice de alguns dos artigos apoia com pertinência a leitura dos mesmos, permitindo ao leitor a visualização dos objetos discutidos. Para além disso, a inclusão tanto dos resumos de cada artigo, como de diferentes índices (onomástico, lugares e manuscritos) são uma excelente ferramenta que facilitam a consulta do volume em questão.

Em suma, o presente volume abre portas para uma visão polifacetada da cultura material da Europa meridional medieval. Procurando estabelecer genealogias de conhecimento e ligações até aqui pouco exploradas, os estudos reunidos neste volume mostram uma Idade Média possuidora de um dinamismo cultural e artístico intenso, uma temática que vale a pena continuar a estudar e explorar.

JOANA MATOS GOMES

Universidade do Porto 